\title{
Prenatal Exposure to Polycyclic Aromatic Hydrocarbons and Birth Weight in China
}

\author{
Qiong Chen ${ }^{1,2}$, Tongzhang Zheng1*, Bryan A. Bassig1, Yibin Cheng3, Brian Leaderer1, \\ Shaobin Lin' ${ }^{3}$, Theodore Holford ${ }^{1}$, Jie Qiu ${ }^{4}$, Yawei Zhang1, Kunchong Shi' ${ }^{5}$, Yong Zhu1, \\ Jianjun $\mathrm{Niu}^{6}$, Yonghong $\mathrm{Li}^{3}$, Huan Guo ${ }^{1,7}$, Xiaobin $\mathrm{Hu}^{1,8}$, Yinlong $\mathrm{Jin}^{3 *}$ \\ ${ }^{1}$ Yale School of Public Health, New Haven, CT, USA \\ ${ }^{2}$ Office for Cancer Research and Control, Cancer Hospital of Henan Province, Affiliated Cancer Hospital of \\ Zhengzhou University, Zhengzhou, China \\ ${ }^{3}$ Institute for Environmental Health and Related Product Safety, Chinese Center for Disease Control and \\ Prevention, Beijing, China \\ ${ }^{4}$ Gansu Provincial Maternity and Child Care Hospital, Lanzhou, China \\ ${ }^{5}$ Department of Healthcare, Beijing Obstetrics and Gynecology Hospital, Capital Medical University, Beijing, \\ China \\ ${ }^{6}$ Xiamen City Center for Disease Control and Prevention, Xiamen, China \\ ${ }^{7}$ Department of Occupational and Environmental Health and Ministry of Education, Key Lab for Environment \\ and Health, School of Public Health, Tongji Medical College, Huazhong University of Science and Technology, \\ Wuhan, China \\ ${ }^{8}$ Department of Epidemiology and Biostatistics, School of Public Health, Lanzhou University, Lanzhou, China \\ Email: Chenq08@126.com, ${ }^{*}$ Tongzhang.zheng@yale.edu, Bassig@yale.edu, Ybcheng123@163.com, \\ Leaderer@yale.edu, 13501260565@163.com, Theodore.Holford@yale.edu, 1239243754@qq.com, \\ Yawei.Zhang@yale.edu, shikunchong@163.com, Yong.Zhu@yale.edu, Niujj365@163.com, \\ Lyh79972002@126.com, Ghuan5011@gmail.com, Huxiaobin@Izu.edu.cn, Jinyinlong1951@yahoo.com.cn
}

Received 27 September 2014; revised 29 October 2014; accepted 13 November 2014

Copyright (C) 2014 by authors and Scientific Research Publishing Inc.

This work is licensed under the Creative Commons Attribution International License (CC BY). http://creativecommons.org/licenses/by/4.0/

(c) (i) Open Access

\section{Abstract}

Adverse birth outcomes are a leading cause of mortality in children in China, but the environmental influences of these conditions remain largely unexplained in this population. We aimed to evaluate the levels of polycyclic aromatic hydrocarbons (PAHs) in Chinese pregnant women and their newborns, and to examine the association between levels of PAHs and infant birth weight. We conducted a cross-sectional study including 81 pairs of mothers and newborns from four hospitals in four different cities in China. High Performance Liquid Chromatography was used to measure the concentration of nine PAHs in maternal and cord blood and multiple linear regression analyses were used to evaluate the associations of these PAHs with infant birth weight. An-

*Corresponding authors.

How to cite this paper: Chen, Q., Zheng, T.Z., Bassig, B.A., Cheng, Y.B., Leaderer, B., Lin, S.B., Holford, T., Qiu, J., Zhang, Y.W., Shi, K.C., Zhu, Y., Niu, J.J., Li, Y.H., Guo, H., Hu, X.B. and Jin, Y.L. (2014) Prenatal Exposure to Polycyclic Aromatic Hydrocarbons and Birth Weight in China. Open Journal of Air Pollution, 3, 100-110. http://dx.doi.org/10.4236/ojap.2014.34010 
thracene (ANT) had the highest average concentration and detection rate (geometric mean = $69.54 \mathrm{ng} / \mathrm{g}$ and $76.5 \%$, respectively) in maternal serum samples, while fluoranthene (FLT) had the highest concentration and detection rate (geometric mean $=68.4 \mathrm{ng} / \mathrm{g}$ and $50.6 \%$, respectively) in the cord blood. Most of the measured PAHs in maternal serum and three PAHs in cord blood were inversely but non-significantly associated with birth weight. The strongest associations were observed for higher concentrations of benzo (a) pyrene (BaP) in maternal serum $(230.7 \mathrm{~g}$ decrease for levels > median vs. < LOD; $p=0.151$ ) and for ANT in cord blood (153.1 $\mathrm{g}$ decrease for levels < median vs. < LOD; $p=0.208$ ). Ant and FLT were the predominant PAHs in the maternal and cord blood serum. Serum concentrations of several measured PAHs were associated with a decreased birth weight, although not significantly, suggesting that further studies with larger sample sizes are needed to validate our findings.

\section{Keywords}

\section{Maternal Exposure, Polycyclic Aromatic Hydrocarbon, Birth Weight, Fetal Development, Maternal Serum}

\section{Introduction}

Polycyclic aromatic hydrocarbons (PAHs) are a large class of chemical compounds and are ubiquitous air pollutants generated from combustion sources [1]. Inhalatory and dermal exposures to PAHs occur among workers in the occupational setting and also among the general population resulting from environmental exposure to tobacco smoke, air pollution, and dietary sources contaminated with PAHs. Some PAHs are human mutagens and carcinogens [1], as well as potentially reproductive and developmental toxicants [2].

As a result of the rapid industrial globalization in China, the annual PAH emission in China was $\sim 114,000$ tons in 2004, accounting for $29 \%$ of the global total [3]. The air concentrations of PAHs reported in monitoring studies are reported to be higher in China compared to other developed countries [4], due in large part to rapid industrialization resulting in increased exposure to car exhaust emissions, coke production, and natural gas combustion [5]. Air monitoring studies have also indicated geographic differences in PAH concentrations within various regions in China, with some studies reporting higher PAH levels in northern compared to southern regions of the country [4]. However, there is limited data on serum levels of PAHs in the Chinese population, which would provide important insight into the internal dose of PAHs in this population and would also take into account different routes of PAH exposure.

Low birth weight and preterm infants are at greater risk for mortality and a variety of health and developmental problems [6]. In China, the leading cause of death for children under 5 years old is premature birth/low birth weight, and thus elucidating the environmental risk factors for these conditions is of great public health interest [7]. Preliminary epidemiologic evidence indicating that exposure to environmental chemicals, such as PAHs, are associated with the development of these birth outcomes suggest the critical need for continued evaluation of this relationship particularly in countries such as China with relatively high levels of exposure [8]-[10].

Recent cohort studies conducted in the United States and Poland have suggested that PAHs adversely impact birth outcomes, contributing to reduced birth weight and length [10], reduced head circumference, and intrauterine growth restriction [2] [9] [11] [12]. Associations between PAH-DNA damage and fetal growth reduction have also been reported in some studies [11] [12]. The levels of PAH-DNA adducts or air monitoring data were mostly used as an indicator of personal exposure to PAHs in these studies, whereas only a few studies have measured serum PAH concentrations as an indicator of exposure [13]-[16].

Only a few studies concerning prenatal exposure to PAHs and fetal growth have been reported in China [17] [18]. Findings from a study conducted at a coal plant in Tongliang suggested that high levels of PAH-DNA adducts in cord blood were associated with fetal and child growth, but the maternal adduct levels were not significantly correlated with the cord blood adduct levels nor significantly associated with fetal and child growth [17]. Given the limited number of studies that have evaluated this association in China, and the significant contribution that adverse birth outcome has on mortality in Chinese children, we evaluated the distributions of PAHs in the maternal and cord blood serum and examined the influence of these exposures on infant birth weight in a 
study of 81 mother and infant pairs from four cities in China.

\section{Materials and Methods}

\subsection{Study Design and Subjects}

Mothers and newborns pairs were randomly selected from hospitalized pregnant women from June to August 2010, a total of 81 pairs of mothers and newborns were enrolled from four hospitals in four different cities of China, including 20 pairs from Beijing, 20 pairs from Lanzhou, 20 pairs from Taiyuan, and 21 pairs from Xiamen. All mothers were interviewed at the time of delivery by a trained interviewer using a standardized questionnaire to collect general information on demographic characteristics (e.g., age, age at menarche, self-reported weight before pregnancy, and height), history of hypertension and diabetes, and lifestyle factors during pregnancy (e.g., smoking and passive smoking, alcohol drinking). Information concerning the mothers' history of congenital diseases, history of adverse pregnancy outcomes (e.g., miscarriage, stillbirth), maternal weight at delivery, and information on the infants' birth date, gender, gestational week, placental weight, and birth weight was obtained from the medical delivery records. A $10 \mathrm{ml}$ sample of peripheral venous blood from the mothers and a $10 \mathrm{ml}$ umbilical cord blood sample was obtained at birth and serum samples were stored at $-70^{\circ} \mathrm{C}$ until analysis. Each of the mothers and their husbands provided informed consent for participation in the study after receiving a detailed explanation of the study. This study was approved by the Human Investigation Committee at Yale University.

\subsection{Measurements of Polycyclic Aromatic Hydrocarbons (PAHs) in Serum}

Nine PAHs were measured in the maternal and cord serum including anthracene (ANT), fluoranthene (FLT), pyrene (PYR), benzo (a) anthracene $(\mathrm{BaA})$, benzo $(\mathrm{k})$ fluoranthene $(\mathrm{BkF})$, benzo (b) fluoranthene $(\mathrm{BbF})$, benzo(a)pyrene (BaP), dibenz (a, h) anthracene (DhA), and benzo (g, h, i) perylene (BgP). A detailed description of the measurement methods for these PAHs was previously reported [19]. Briefly, $5.0 \mathrm{ml}$ of methanol and $5.0 \mathrm{ml}$ of high purity water were used to activate the Solid Phase Extraction (SPE) cartridges, and then the 1.0 $\mathrm{ml}$ serum sample was loaded on a cartridge and extraction solution $(1.0 \mathrm{ml}$ ultrapure water) was aspirated through the cartridge, dried by nitrogen for $20 \mathrm{~min}$, and then eluted with $2.0 \mathrm{ml}$ ethyl acetate. The mixture was then concentrated (Concentrator, Thermo Fisher Scientific) at $35^{\circ} \mathrm{C}$ for 1 hour, diluted with methanol to $100 \mu \mathrm{L}$, and centrifuged (centrifugal machine, Sigma) at $5000 \mathrm{r} / \mathrm{min}$ for $10 \mathrm{~min}$. The resulting supernatant liquid was analyzed using High Performance Liquid Chromatography (HPLC).

The aliquot of the final sample extracts was analyzed on an HPLC system (2695 series; Waters, Milford, MA, USA) equipped with a fluorescence detector (Model 474; Waters, USA), using an automatic solid phase extraction apparatus (Gilson GX274) for all PAHs. The solvent system that constituted the mobile phase was acetonitrile (A) and water (B) and was run in gradient mode. The detection wavelength of excitation and emission was $345 \mathrm{~nm}$ and $425 \mathrm{~nm}$, respectively. The elution conditions were as follows: 0 - $20 \mathrm{~min}, 60 \% \mathrm{~A} ; 20$ - $40 \mathrm{~min}$, linear gradient $60 \% \mathrm{~A}-100 \% \mathrm{~A}$; and $40-45 \mathrm{~min}, 100 \% \mathrm{~A}$ isocratic. The flow rate was maintained at $1.0 \mathrm{ml} / \mathrm{min}$ throughout the analysis and the injection volume was $20 \mu \mathrm{l}$. The limits of detection (LOD) for the serum concentrations of each PAH are listed in Table 3.

\subsection{Measurements of Lipids in Serum}

We report the total lipid calibrated concentrations of serum PAHs, which were expressed as ng/g of lipid. The blood lipids were measured using standard enzymatic methods, and an established summation formula was used to calculate the total serum lipids of each sample [20].

\subsection{Quality Control}

Recovery experiments were conducted to check the analytic quality control, using 10 calf serum samples that were spiked with mixed standards of PAHs at 1 - $10 \mathrm{ng}$. The average recoveries for the nine measured PAHs varied from $91.4 \%$ to $99.8 \%$ and the relative standard deviation ranged from $2.88 \%$ to $12.70 \%$. The limits of detection in spiked samples ranged from 0.05 to $0.10 \mathrm{ng} / \mathrm{ml}$ for nine PAHs during HPLC analysis. The maximum linear range of $0.10-3.0 \mathrm{ng} / \mathrm{ml}$ was found for nine PAHs, and the correlation coefficient ranged from 0.9941 to 
0.9999. A blank sample was prepared and run with each set of samples during PAH analyses by HPLC.

\subsection{Statistical Analysis}

The geometric mean (GM), median, minimum, and maximum values of the lipid adjusted concentrations of each $\mathrm{PAH}$ in maternal and cord blood serum were calculated and used as summary statistics, and the differences in concentration between the maternal and cord blood serum for each of the PAHs were analyzed by the Wilcoxon matched-paired signed-ranks test. PAH values below LOD were replaced with $50 \%$ of the LOD value in the analyses. The concentration of samples above LOD for each PAH was divided into two groups based on the median, with values below LOD used as the reference. Multivariate linear regression models were utilized in order to evaluate the associations between the concentrations of each PAH and infant birth weight. Potential confounders were included in the multivariate models if they were related to birth weight or if their absence significantly affected the estimated PAH effect ( $\geq 10 \%$ change). Maternal age, BMI, gestational week, and infant gender met these criteria and were adjusted for in the final models. The regression analyses were only carried out for PAHs with detection rates $>15 \%$ in the maternal serum and cord blood serum. All data analyses were carried out with Statistical Analysis Software version 9.3 (SAS Institute, Cary, NC), and a two-sided p $<0.05$ was considered statistically significant.

\section{Results}

\subsection{Characteristics of Participants}

General characteristics of the 81 healthy mother/infant pairs are shown in Table 1 . The median age of the mothers was 28 years old, ranging from 18 to 44 years, and the majority of mothers were not exposed to passive smoking ( $\sim 89 \%)$. None of mothers smoke themselves or use alcohol. $63 \%$ of the newborns were female and $\sim 86 \%$ of infants were born after a full-term (i.e., $\geq 37$ weeks) and had a birth weight of 2500 - $4000 \mathrm{~g}$ (Table 1).

\subsection{PAH Detection Rates}

The detection rates for each PAH in the maternal and infant cord serum are shown in Table 2. In the maternal serum, ANT, BkF, DhA, and FLT were detected in more than $40 \%$ of the samples, with the highest detection rate observed for ANT (76.5\%) followed by BkF (60.7\%), DhA (48.2\%), and FLT (46.9\%). Detection rates of the other measured PAHs were all $>10 \%$ in the maternal serum samples.

In the cord blood, FLT had the highest detection rate of $50.6 \%$, which was slightly but non-significantly higher compared to detection rates in maternal blood for this PAH. Detection rates of $>20 \%$ in the cord blood samples were similarly observed for BkF (44.4\%), ANT (37.0\%), and BgP (21.0\%), while only a few cord blood samples had detectable levels of $\operatorname{BaA}(n=1,1.2 \%), \operatorname{BbF}(n=3,3.7 \%)$ and $\operatorname{BaP}(n=3,3.7 \%)$. Compared with the detection rates in the cord blood, all of the measured PAHs were statistically significantly higher in the maternal serum, with the exception of FLT (maternal: 46.9\%; cord blood: 50.6\%; p = 0.637) and BgP (maternal: 23.5\%; cord blood: 21.0\%; $\mathrm{p}=0.706$ ).

\subsection{PAH Concentrations in Maternal and Cord Blood}

The GM, median, minimum, and maximum values for each PAH concentration are shown in Table 3. Of the measured PAHs, the concentration of ANT was the highest in maternal serum (GM for lipid adjusted 69.54 ng/g), followed by DhA (40.5 ng/g), BkF (30.0 ng/g) and FLT (30.0 ng/g). FLT had the highest concentration in cord blood (68.4 ng/g) relative to other PAHs, followed by ANT (50.40 ng/g) and DhA (50.20 ng/g). Except for FLT, all of the PAHs measured in cord blood had median concentrations below the limitation of detection.

Comparing the lipid adjusted concentration of each PAH in the maternal and cord serum, the concentrations of all PAHs were higher in the cord blood except for ANT, for which the GM concentration was significantly higher in the maternal serum (maternal GM: $69.5 \mathrm{ng} / \mathrm{g}$; cord blood GM: $50.4 \mathrm{ng} / \mathrm{g}$; p < 0.001). Conversely, the lipid adjusted GM concentrations of FLT, PYR, BaA, BbF, BaP, and BgP were all significantly higher in the cord blood samples.

The lipid adjusted concentrations of all the measured PAHs in maternal serum were significantly correlated with that in cord blood, except for FLT $(r=-0.06, \mathrm{p}=0.593)$, PYR $(\mathrm{r}=0.13, \mathrm{p}=0.263)$ and DbA $(\mathrm{r}=0.2, \mathrm{p}=$ 
Table 1. General characteristics of 81 pairs of mothers and newborns.

\begin{tabular}{|c|c|c|}
\hline Characteristics & $\mathbf{N}$ & Median (min - max) or \% \\
\hline \multicolumn{3}{|l|}{ Maternal parameters } \\
\hline Age (years) & 81 & $28.5(18.0-44.0)$ \\
\hline \multicolumn{3}{|l|}{ BMI $\left(\mathrm{kg} / \mathrm{m}^{2}\right)$} \\
\hline Pre-pregnancy & 81 & $20.6(15.6-35.3)$ \\
\hline At delivery & 81 & $26.7(18.9-39.6)$ \\
\hline Smoking & 0 & 0 \\
\hline Alcohol drinking & 0 & 0 \\
\hline \multicolumn{3}{|l|}{ Passive smoking } \\
\hline Yes & 9 & $11.1 \%$ \\
\hline No & 72 & $88.9 \%$ \\
\hline Menarche age & 73 & $14.0(11.0-19.0)$ \\
\hline \multicolumn{3}{|l|}{ Infant parameters } \\
\hline \multicolumn{3}{|l|}{ Sex } \\
\hline Boys & 30 & $37.0 \%$ \\
\hline Girls & 51 & $63.0 \%$ \\
\hline Term (weeks) & 81 & $39.0(31.0$ - 41.0) \\
\hline$<37$ & 11 & $13.6 \%$ \\
\hline$\geq 37$ & 70 & $86.4 \%$ \\
\hline Birth weight (g) & 81 & $3300(1400-4450)$ \\
\hline$<2500$ & 8 & $9.9 \%$ \\
\hline $2500-4000$ & 70 & $86.4 \%$ \\
\hline$>4000$ & 3 & $3.7 \%$ \\
\hline
\end{tabular}

Table 2. Number and detection rates of PAHs in maternal and cord blood.

\begin{tabular}{|c|c|c|c|c|c|c|c|c|}
\hline \multirow{2}{*}{ PAHs } & \multicolumn{2}{|c|}{ Mother (81) } & \multicolumn{2}{|c|}{ Newborns (81) } & \multirow{2}{*}{$\chi^{2}$} & \multirow{2}{*}{$\mathrm{p}$} & \multirow{2}{*}{$\mathrm{r}$} & \multirow{2}{*}{$\mathrm{p}$} \\
\hline & $\mathrm{n}$ & Detection rate & $\mathrm{n}$ & Detection rate & & & & \\
\hline AnT & 62 & 76.54 & 30 & 37.04 & 25.76 & $<0.001$ & 0.22 & 0.049 \\
\hline FLT & 38 & 46.91 & 41 & 50.62 & 0.22 & 0.637 & -0.06 & 0.593 \\
\hline PYR & 21 & 25.93 & 10 & 12.35 & 4.83 & 0.028 & 0.13 & 0.263 \\
\hline $\mathbf{B a A}$ & 9 & 11.11 & 1 & 1.23 & 6.82 & 0.009 & 0.29 & 0.009 \\
\hline BbF & 15 & 18.52 & 3 & 3.70 & 9.00 & 0.002 & 0.33 & 0.002 \\
\hline BkF & 50 & 61.73 & 36 & 44.44 & 4.86 & 0.028 & 0.39 & $<0.001$ \\
\hline BaP & 14 & 17.28 & 3 & 3.70 & 7.95 & 0.005 & 0.24 & 0.030 \\
\hline DbA & 39 & 48.15 & 11 & 13.58 & 22.68 & $<0.001$ & 0.20 & 0.069 \\
\hline BgP & 19 & 23.46 & 17 & 20.99 & 0.14 & 0.706 & 0.37 & $<0.001$ \\
\hline
\end{tabular}


Table 3. Lipid-adjusted PAHs concentrations (ng $\cdot \mathrm{g}^{-1}$ lipid) in maternal and cord blood.

\begin{tabular}{|c|c|c|c|c|c|c|c|c|}
\hline \multirow{2}{*}{ PAHs } & \multirow{2}{*}{ Limit (ng/ml) } & \multicolumn{3}{|c|}{ Mothers (81) } & \multicolumn{3}{|c|}{ Newborns (81) } & \multirow{2}{*}{ p value } \\
\hline & & GM & Median & Max & GM & Median & Max & \\
\hline AnT & 0.07 & 69.54 & 84.57 & 887.09 & 50.40 & $<\mathrm{LOD}$ & 320.29 & $<0.001$ \\
\hline FLT & 0.05 & 29.73 & $<\mathrm{LOD}$ & 891.14 & 68.44 & 37.73 & 1301.57 & 0.004 \\
\hline PYR & 0.07 & 20.96 & $<\mathrm{LOD}$ & 484.33 & 36.64 & $<\mathrm{LOD}$ & 560.40 & 0.012 \\
\hline BaA & 0.09 & 20.96 & $<\mathrm{LOD}$ & 616.45 & 37.90 & $<\mathrm{LOD}$ & 136.52 & $<0.001$ \\
\hline BbF & 0.05 & 16.04 & $<\mathrm{LOD}$ & 1005.16 & 22.94 & $<\mathrm{LOD}$ & 553.25 & 0.007 \\
\hline BkF & 0.05 & 29.95 & 33.25 & 389.50 & 38.96 & $<\mathrm{LOD}$ & 208.68 & 0.609 \\
\hline BaP & 0.10 & 22.59 & $<$ LOD & 200.58 & 43.07 & $<\mathrm{LOD}$ & 96.51 & $<0.001$ \\
\hline DhA & 0.10 & 40.49 & $<\mathrm{LOD}$ & 393.09 & 50.20 & $<\mathrm{LOD}$ & 486.54 & 0.825 \\
\hline BgP & 0.07 & 18.37 & $<\mathrm{LOD}$ & 875.79 & 43.01 & $<\mathrm{LOD}$ & 700.18 & $<0.001$ \\
\hline
\end{tabular}

0.069). The correlation coefficients varied from 0.22 to 0.39 ( $\mathrm{p}<0.05$ ) (Table 2).

The descriptive statistics of each PAH concentration separately for the four cities are shown in supplementary Table 1 and Table 2.

\subsection{Associations between Maternal and Cord Serum Concentrations of PAHs and Birth Weight}

The associations between infant birth weight and concentrations of each of the PAHs in maternal serum and in cord blood samples, adjusted for the gender of the infant, maternal age, gestational week, and maternal BMI, are shown in Table 4. No significant associations were observed between these PAHs and birth weight, however, we found inverse associations with birth weight for concentrations of all but one PAH in maternal serum (reduction in birth weight $(\mathrm{g})$ compared to the reference group with concentrations < LOD: FLT $71.4 \mathrm{~g}(\mathrm{p}=0.486$ ), PYR $71.6 \mathrm{~g}(\mathrm{p}=0.586)$, DhA $65.6 \mathrm{~g}(\mathrm{p}=0.536)$, and BaP $230.7 \mathrm{~g}(\mathrm{p}=0.151)$ for the greater than median group; BbF 179.7 g ( $=0.197)$, BgP $68.0 \mathrm{~g}(\mathrm{p}=0.611)$, and BaP $37.5 \mathrm{~g}(\mathrm{p}=0.818)$ for the less than median group). Concentrations of ANT, FLT, and BkF in the cord blood samples were also inversely associated with birth weight, although these reductions were not statistically significant. Specifically, a $49.6 \mathrm{~g}(\mathrm{p}=0.646)$ and $75.7 \mathrm{~g}$ $(p=0.496)$ decrease in birth weight was observed in infants with concentrations of BkF less than the median and greater than the median, respectively, compared with the reference group. We further observed a $153.1 \mathrm{~g}(\mathrm{p}$ $=0.208)$ decrease in birth weight for infants with ANT levels less than the median and a $48.3 \mathrm{~g}(\mathrm{p}=0.675)$ decrease in birth weight for infants with FLT levels greater than the median, compared to the reference group with levels $<$ LOD.

\section{Discussion}

A few previous studies have evaluated the serum concentrations of PAHs among mothers and their infants in China [13]-[16], and related these exposure levels with infant birth weight [17]. The results of our study suggested that the detection rates of most measured PAHs, with the exception of FLT and BgP, were significantly higher in the maternal blood than in the cord blood, and that ANT and FLT were the predominant PAHs in the maternal and cord blood serum, respectively. Further, we found an inverse relationship between all measured PAHs in the maternal serum, except for ANT, and infant birth weight although the associations were not statistically significant.

Studies have found that PAHs can cross the placental barrier and can cause adverse health effects in the fetus [21] [22]. In particular, epidemiologic studies have suggested that PAHs are significantly associated with low birth weight, reduced head circumference, preterm and intrauterine growth restriction (IUGR) [9] [23]. Among these studies, measurements of personal exposure have been estimated by either air monitoring or measuring le- 
Table 4. Multiple linear regression analysis for birth weight in relation to PAH concentrations in maternal blood and cord blood.

\begin{tabular}{|c|c|c|c|c|c|c|c|c|}
\hline \multirow{2}{*}{ PAHs } & \multicolumn{4}{|c|}{ Mother } & \multicolumn{4}{|c|}{ Newborns } \\
\hline & & Beta $^{\dagger}$ & $95 \% \mathrm{CI}$ & p value & & Beta $^{\dagger}$ & $95 \% \mathrm{CI}$ & p value \\
\hline \multirow[t]{4}{*}{ AnT } & $<\mathrm{LOD}$ & 1 & 1 & 1 & $<\mathrm{LOD}$ & 1 & 1 & 1 \\
\hline & $23.3-130.5$ & 26.8 & $(-183.4-236.9)$ & 0.800 & $64.7-131.7$ & -153.1 & $(-393.4-87.2)$ & 0.208 \\
\hline & $>130.5$ & 148.1 & $(-68.5-364.6)$ & 0.177 & $>131.7$ & 104.2 & $(-110.6-319.1)$ & 0.337 \\
\hline & $\mathrm{p}$ for trend & & & 0.172 & $\mathrm{p}$ for trend & & & 0.590 \\
\hline \multirow[t]{4}{*}{ FLT } & $<\mathrm{LOD}$ & 1 & 1 & 1 & $<\mathrm{LOD}$ & 1 & 1 & 1 \\
\hline & $20.0-154.0$ & 112.8 & $(-100.7-326.3)$ & 0.295 & $37-202.6$ & 67.4 & $(-165.0-299.7)$ & 0.565 \\
\hline & $>154.0$ & -71.4 & $(-275.0-132.1)$ & 0.486 & $>202.6$ & -48.3 & $(-277.2-180.7)$ & 0.675 \\
\hline & $\mathrm{p}$ for trend & & & 0.686 & $\mathrm{p}$ for trend & & & 0.485 \\
\hline \multirow[t]{4}{*}{ PYR } & $<\mathrm{LOD}$ & 1 & 1 & 1 & & & & \\
\hline & $31.0-148.8$ & 24.8 & $(-239.2-288.8)$ & 0.852 & - & - & - & - \\
\hline & $>148.8$ & -71.6 & $(-332.5-189.4)$ & 0.586 & - & - & - & - \\
\hline & $\mathrm{p}$ for trend & & & 0.674 & & & & \\
\hline \multirow[t]{4}{*}{$\mathrm{BbF}$} & $<\mathrm{LOD}$ & 1 & 1 & 1 & & & & \\
\hline & $64.0-310.2$ & -179.7 & $(-455.0-95.6)$ & 0.197 & - & - & - & - \\
\hline & $>310.2$ & 44.6 & $(-246.0-335.1)$ & 0.761 & - & - & - & - \\
\hline & $\mathrm{p}$ for trend & & & 0.809 & & & & \\
\hline \multirow[t]{4}{*}{$\mathrm{BkF}$} & $<\mathrm{LOD}$ & 1 & 1 & 1 & $<\mathrm{LOD}$ & 1 & 1 & 1 \\
\hline & $19.9-84.0$ & 81.7 & $(-134.3-297.7)$ & 0.453 & $42.0-99.7$ & -49.6 & $(-264.3-165.0)$ & 0.646 \\
\hline & $>84.0$ & 52.2 & $(-151.1-255.4)$ & 0.610 & $>99.7$ & -75.7 & $(-296.3-144.9)$ & 0.496 \\
\hline & $\mathrm{p}$ for trend & & & 0.585 & $\mathrm{p}$ for trend & & & 0.452 \\
\hline \multirow[t]{4}{*}{$\mathrm{BaP}$} & $<\mathrm{LOD}$ & 1 & 1 & 1 & - & - & - & - \\
\hline & $58.0-83.4$ & -37.5 & $(-361.1-286.0)$ & 0.818 & - & - & - & - \\
\hline & $>83.4$ & -230.7 & $(-547.8-86.4)$ & 0.151 & - & - & - & - \\
\hline & $\mathrm{p}$ for trend & & & 0.169 & & & & \\
\hline \multirow[t]{4}{*}{ DhA } & $<$ LOD & 1 & 1 & 1 & - & - & - & - \\
\hline & $47.4-121.7$ & 144.6 & $(-64.7-354.0)$ & 0.173 & - & - & - & - \\
\hline & $>121.7$ & -65.6 & $(-275.9-144.7)$ & 0.536 & - & - & - & - \\
\hline & $\mathrm{p}$ for trend & & & 0.829 & & & & \\
\hline \multirow[t]{4}{*}{$\mathrm{BgP}$} & $<$ LOD & 1 & 1 & 1 & $<$ LOD & 1 & 1 & 1 \\
\hline & $26.2-87.4$ & -68.0 & $(-333.2-197.2)$ & 0.611 & $56.0-185.3$ & 188.6 & $(-77.2-454.5)$ & 0.161 \\
\hline & $>87.4$ & 17.9 & $(-272.0-236.1)$ & 0.888 & $>185.3$ & 37.6 & $(-259.2-334.5)$ & 0.801 \\
\hline & $\mathrm{p}$ for trend & & & 0.766 & $\mathrm{p}$ for trend & & & 0.429 \\
\hline
\end{tabular}

${ }^{\dagger}$ Adjusted for infant gender, maternal age, gestational week, and maternal BMI. 
vels of PAH-DNA adducts. In the U.S. and Polish cohort study, the average PAH concentration in Krakow estimated by personal monitoring was $39 \mathrm{ng} / \mathrm{m}^{3}$ (range, $1.8-272.2 \mathrm{ng} / \mathrm{m}^{3}$ ), and $3.3 \mathrm{ng} / \mathrm{m}^{3}$ (range, $0.3-36.5 \mathrm{ng} / \mathrm{m}^{3}$ ) in New York City (NYC). A significant reduction in birth weight was found both in Krakow and in African Americans living in NYC [10]. In Beijing, the average air concentration of PAHs in the spring, summer, autumn, and winter was $46 \mathrm{ng} / \mathrm{m}^{3}, 16 \mathrm{ng} / \mathrm{m}^{3}, 52 \mathrm{ng} / \mathrm{m}^{3}, 268 \mathrm{ng} / \mathrm{m}^{3}$, respectively, which are higher levels compared to those reported in the developed countries, but this previous Chinese study did not evaluate the effect of PAH exposure on birth outcomes [24].

For the lipid adjusted concentrations, all of the PAHs were higher in cord blood than in maternal serum except for ANT. Other studies have also found higher concentrations of PAHs in cord blood, which could be because PAHs are generally bound extensively to lipoproteins [25] [26] and, as levels of these have been reported to be higher in newborns than in maternal blood [27], PAHs may accumulate more easily in infants. Another potential reason for this observation could be that PAHs are metabolized slower in the fetus due to age related differences in enzyme function [28].

Recently, several studies conducted in China have assessed PAH levels in the general population [13]-[16] (Table 5). It is difficult to compare our data with those from other studies due to the presentation of the results in different units (e.g., ng/g lipid vs. ppb). Some notable differences in the concentrations of specific PAHs were observed in our study compared with a previous study conducted in Hong Kong [13]. Specifically, whereas BaP,

Table 5. Comparisons of PAHs in maternal serum and cord serum of different studies in China.

\begin{tabular}{|c|c|c|c|c|c|c|c|}
\hline & Sample & Study 1 & Study 2 & \multicolumn{2}{|c|}{ Study 3} & Study 4 & Study 5 \\
\hline Reference NO. & & & 13 & \multicolumn{2}{|c|}{14} & 15 & 16 \\
\hline Location & & Our result & Hongkang & Guiyu & Chaonan & Beijing & Taiyuan \\
\hline Sample size & & 81 & 21 & 103 & 80 & 40 & 271 \\
\hline \multirow[t]{2}{*}{ Unit } & & ng/g & ng/g & ppb & ppb & $n g / g$ & $\mu \mathrm{g} / \mathrm{L}$ \\
\hline & & Mean (Median) & Mean \pm SD & Median & Median & Mean \pm SD & Mean (Median) \\
\hline \multirow{2}{*}{ Ant } & Maternal serum & 69.5 (84.6) & $48 \pm 25$ & - & - & - & - \\
\hline & Cord blood & 50.4 (<LOD) & $37 \pm 27$ & - & - & $117 \pm 104$ & - \\
\hline \multirow{2}{*}{ FLT } & Maternal serum & 29.7 (<LOD) & $128 \pm 90$ & - & - & - & - \\
\hline & Cord blood & $68.4(37.7)$ & $89 \pm 46$ & - & - & $283 \pm 355$ & - \\
\hline \multirow{2}{*}{ PYR } & Maternal serum & 21.0 (<LOD) & $154 \pm 137$ & - & - & - & $0.56(0.34)$ \\
\hline & Cord blood & 36.6 (<LOD) & $98 \pm 88$ & - & - & $236 \pm 271$ & $0.58(0.34)$ \\
\hline \multirow{2}{*}{$\mathrm{BaA}$} & Maternal serum & 21.0 (<LOD) & $63 \pm 34$ & 0.83 & 0.43 & - & $0.88(0.64)$ \\
\hline & Cord blood & $37.9(<$ LOD $)$ & $80 \pm 32$ & - & - & $73.4 \pm 120$ & $0.82(0.71)$ \\
\hline \multirow{2}{*}{$\mathrm{BbF}$} & Maternal serum & $16.0(<\mathrm{LOD})$ & BbkF & - & - & - & $0.25(0.16)$ \\
\hline & Cord blood & $22.9(<$ LOD $)$ & $16 \pm 10$ & 51.99 & 40.09 & $214 \pm 450$ & $0.32(0.16)$ \\
\hline \multirow{2}{*}{$\mathrm{BkF}$} & Maternal serum & $30.0(33.2)$ & BbkF & - & - & - & $0.27(0.31)$ \\
\hline & Cord blood & $39.0(<\mathrm{LOD})$ & $20 \pm 26$ & - & - & $85.5 \pm 181$ & $0.34(0.36)$ \\
\hline \multirow{2}{*}{$\mathrm{BaP}$} & Maternal serum & 22.6 (<LOD) & $<\mathrm{LOD}$ & - & - & - & $0.16(0.15)$ \\
\hline & Cord blood & 43.1 (<LOD) & $<\mathrm{LOD}$ & 2.14 & 1.64 & $16.2 \pm 39.3$ & $0.19(0.15)$ \\
\hline \multirow{2}{*}{ DhA } & Maternal serum & 40.5 (<LOD) & - & - & - & - & $0.03(0.02)$ \\
\hline & Cord blood & $50.2(<$ LOD $)$ & - & - & - & - & $0.03(0.02)$ \\
\hline \multirow{2}{*}{$\mathrm{BgP}$} & Maternal serum & 18.4 (<LOD) & - & - & - & & $0.11(0.03)$ \\
\hline & Cord blood & 43.0 (<LOD) & - & - & - & $10.3 \pm 27.9$ & $0.16(0.03)$ \\
\hline
\end{tabular}


DhA, BgP were detected in around 20\% of samples in our study, these PAHs were not detected in the participants in the Hong Kong study. Moreover, the average level of ANT (maternal serum: $48 \pm 25 \mathrm{ng} / \mathrm{g}$, cord serum: $37 \pm 27 \mathrm{ng} / \mathrm{g}$ ) in the Hong Kong study was lower compared to in our study, while the concentrations of Flu (maternal serum: $128 \pm 90 \mathrm{ng} / \mathrm{g}$, cord serum: $89 \pm 46 \mathrm{ng} / \mathrm{g}$ ), PYR (maternal serum: $154 \pm 137 \mathrm{ng} / \mathrm{g}$, cord serum: $98 \pm$ $88 \mathrm{ng} / \mathrm{g}$ ) and BaA (maternal serum: $63 \pm 34 \mathrm{ng} / \mathrm{g}$, cord serum: $80 \pm 32 \mathrm{ng} / \mathrm{g}$ ) were higher than in our study.

Previous studies have reported a reduction in birth weight associated with exposure to PAHs. For example, a significant reduction in birth weight was previously associated with barbecued meat consumption, an important dietary source of PAH exposure, during pregnancy [29]. PAH exposure has also been identified as an independent determinant of birth outcomes based on results from a US cohort study [2], as higher exposure to PAHs in African Americans was associated with lower birth weight $(\mathrm{p}=0.003)$ after adjustment for other confounders associated with birth weight. Further, results from a cohort study of 344 healthy pregnant women reported that prenatal exposure to PAHs during the first trimester was associated with the largest decrement in the fetal growth ratio (FGR) and birth weight, relative to subsequent trimesters, suggesting that exposures early in the pregnancy may be the most relevant window period for resulting effects on birth outcomes [30].

Despite this suggestive evidence, reductions in birth weight due to prenatal exposure to PAHs have not been apparent in all studies [2] [10] [17]. The inconsistent associations may be due to differences in susceptibility to the adverse effects from these exposures and/or due to differences in PAH exposure levels across populations. In addition, due to the variability of the exposure route, the levels of personal PAH exposure may be biased by the method used for the measurement in different studies. For example, PAH exposure in humans mainly occurs from intake of food contaminated with these chemicals, and as a result exposure levels estimated by air monitoring might not reflect the true body burden of exposure. Some internal indicators of exposure, such as measurement of PAH-DNA adducts or metabolites detectable in blood or urine [17], may be useful in improving the PAH exposure assessments.

\section{Conclusion}

In conclusion, a decreased infant birth weight was associated with increased serum concentrations of several PAHs measured in our study, including FLT, PYR, BbF, BkF, BaP, DhA, and BgP. However, due to the limited sample size of the present study, we did not find a significant association. Therefore, further well-designed studies with large sample sizes are needed to verify our results.

\section{Highlights}

Prenatal exposure to polycyclic aromatic hydrocarbons was shown to affect fetal growth. Serum levels of 9 PAHs were measured in 81 mother-infant pairs.

Ant and FLT were the predominant PAHs in the maternal and cord blood serum.

FLT, PYR, BbF, BkF, BaP, DhA, and BgP were associated with decreased birth weight.

\section{Conflict of Interest}

The authors declared no potential competing financial interests.

\section{Funding}

This work was partly supported by Fogarty training grants D43TW 008323 and D43TW 007864-01 from the National Institutes of Health (T. Zheng).

\section{Acknowledgements}

The authors would particularly like to thank all the participants for their generous collaboration.

\section{References}

[1] Bostrom, C.E., Gerde, P., Hanberg, A., Jernstrom, B., Johansson, C., Kyrklund, T., et al. (2002) Cancer Risk Assessment, Indicators, and Guidelines for Polycyclic Aromatic Hydrocarbons in the Ambient Air. Environmental Health Perspectives, 110, 451-488. http://dx.doi.org/10.1289/ehp.02110s3451 
[2] Perera, F.P., Rauh, V., Tsai, W.Y., Kinney, P., Camann, D., Barr, D., et al. (2003) Effects of Transplacental Exposure to Environmental Pollutants on Birth Outcomes in a Multiethnic Population. Environmental Health Perspectives, 111, 201-205. http://dx.doi.org/10.1289/ehp.5742

[3] Shen, H., Huang, Y., Wang, R., Zhu, D., Li, W., Shen, G., et al. (2013) Global Atmospheric Emissions of Polycyclic Aromatic Hydrocarbons from 1960 to 2008 and Future Predictions. Environmental Science \& Technology, 47, 64156424.

[4] Liu, S., Tao, S., Liu, W., Liu, Y., Dou, H., Zhao, J., et al. (2007) Atmospheric Polycyclic Aromatic Hydrocarbons in North China: A Winter-Time Study. Environmental Science \& Technology, 41, 8256-8261. http://dx.doi.org/10.1021/es0716249

[5] Zhang, S., Zhang, W., Wang, K., Shen, Y., Hu, L. and Wang, X. (2009) Concentration, Distribution and Source Apportionment of Atmospheric Polycyclic Aromatic Hydrocarbons in the Southeast Suburb of Beijing, China. Environmental Monitoring and Assessment, 151, 197-207. http://dx.doi.org/10.1007/s10661-008-0261-2

[6] Mathews, T.J. and MacDorman, M.F. (2008) Infant Mortality Statistics from the 2005 Period Linked Birth/Infant Death Data Set. National Vital Statistics Reports: From the Centers for Disease Control and Prevention, National Center for Health Statistics, National Vital Statistics System, 57, 1-32.

[7] Feng, J., Yuan, X.Q., Zhu, J., Li, X.H., Miao, L., He, C.H., et al. (2012) Under-5-Mortality Rate and Causes of Death in China, 2000 to 2010. Zhonghua Liu Xing Bing Xue Za Zhi, 33, 558-561.

[8] Wang, J.Z., Zhu, C.Z. and Chen, T.H. (2013) PAHs in the Chinese Environment: Levels, Inventory Mass, Source and Toxic Potency Assessment. Environmental Science Processes \& Impacts, 15, 1104-1112.

[9] Choi, H., Rauh, V., Garfinkel, R., Tu, Y. and Perera, F.P. (2008) Prenatal Exposure to Airborne Polycyclic Aromatic Hydrocarbons and Risk of Intrauterine Growth Restriction. Environmental Health Perspectives, 116, 658-665. http://dx.doi.org/10.1289/ehp.10958

[10] Choi, H., Jedrychowski, W., Spengler, J., Camann, D.E., Whyatt, R.M., Rauh, V., et al. (2006) International Studies of Prenatal Exposure to Polycyclic Aromatic Hydrocarbons and Fetal Growth. Environmental Health Perspectives, 114, 1744-1750.

[11] Perera, F.P., Whyatt, R.M., Jedrychowski, W., Rauh, V., Manchester, D., Santella, R.M., et al. (1998) Recent Developments in Molecular Epidemiology: A Study of the Effects of Environmental Polycyclic Aromatic Hydrocarbons on Birth Outcomes in Poland. American Journal of Epidemiology, 147, 309-314. http://dx.doi.org/10.1093/oxfordjournals.aje.a009451

[12] Perera, F.P., Tang, D.L., Rauh, V., Lester, K., Tsai, W.Y., Tu, Y.H., et al. (2005) Relationships among Polycyclic Aromatic Hydrocarbon-DNA Adducts, Proximity to the World Trade Center, and Effects on Fetal Growth. Environmental Health Perspectives, 113, 1062-1067. http://dx.doi.org/10.1289/ehp.7908

[13] Tsang, H.L., Wu, S.C., Leung, C.K., Tao, S. and Wong, M.H. (2011) Body Burden of POPs of Hong Kong Residents, Based on Human Milk, Maternal and Cord Serum. Environment International, 37, 142-151. http://dx.doi.org/10.1016/j.envint.2010.08.010

[14] Guo, Y.Y., Huo, X., Wu, K.S., Liu, J.X., Zhang, Y.L. and Xu, X.J. (2012) Carcinogenic Polycyclic Aromatic Hydrocarbons in Umbilical Cord Blood of Human Neonates from Guiyu, China. The Science of the Total Environment, 427-428, 35-40. http://dx.doi.org/10.1016/j.scitotenv.2012.04.007

[15] Yu, Y.X., Wang, X.L., Wang, B., Tao, S., Liu, W.X., Wang, X.J., et al. (2011) Polycyclic Aromatic Hydrocarbon Residues in Human Milk, Placenta, and Umbilical Cord Blood in Beijing, China. Environmental Science \& Technology, 45, 10235-10242. http://dx.doi.org/10.1021/es202827g

[16] Dong, S., Ding, C., Zhang, M. and Liu, Y. (2009) Relationship of PAHs Levels in Umbilical Cord Blood and the PAHs Exposure between the Mother and the Paired Newborns. Journal of Hygiene Research, 38, 339-342.

[17] Tang, D.L., Li, T.Y., Liu, J.J., Chen, Y.H., Qu, L.R. and Perera, F. (2006) PAH-DNA Adducts in Cord Blood and Fetal and Child Development in a Chinese Cohort. Environmental Health Perspectives, 114, 1297-1300. http://dx.doi.org/10.1289/ehp.8939

[18] Tang, D.L., Li, T.Y., Chow, J.C., Kulkarni, S.U., Watson, J.G., Ho, S.S., et al. (2014) Air Pollution Effects on Fetal and Child Development: A Cohort Comparison in China. Environmental Pollution, 185, 90-96. http://dx.doi.org/10.1016/j.envpol.2013.10.019

[19] Ding, C., Zheng, L. and Lin, S. (2012) Determination of Nine Kinds of Polycyclic Aromatic Hydrocarbons in Serum by High Performance Liquid Chromatography. Journal of Hygiene Research, 41, 850-853.

[20] Rylander, L., Nilsson-Ehle, P. and Hagmar, L. (2006) A Simplified Precise Method for Adjusting Serum Levels of Persistent Organohalogen Pollutants to Total Serum Lipids. Chemosphere, 62, 333-336. http://dx.doi.org/10.1016/j.chemosphere.2005.04.107

[21] The International Agency for Research on Cancer (1983) Polynuclear Aromatic Compounds, Part 1, Chemical, Envi- 
ronmental and Experimental Data. IARC Monographs on the Evaluation of the Carcinogenic Risk of Chemicals to Humans, 32, 1-453.

[22] WHO (2000) Air Quality Guidelines for Europe. WHO Regional Publications, European Series, No. 91, V-X, 1-273.

[23] Dejmek, J., Solansky, I., Benes, I., Lenicek, J. and Sram, R.J. (2000) The Impact of Polycyclic Aromatic Hydrocarbons and Fine Particles on Pregnancy Outcome. Environmental Health Perspectives, 108, 1159-1164.

[24] Zhang, D.H., Ma, Y.L., He, K.B., Duan, F.K., Jia, Y.T., Okuda, T., et al. (2006) Characteristics of Polycyclic Aromatic Hydrocarbons (PAHS) on Airborne Particulates in Beijing. Environmental Science, 27, 1269-1275.

[25] Aarstad, K., Toftgard, R. and Nilsen, O.G. (1987) A Comparison of the Binding and Distribution of Benzo[a]Pyrene in Human and Rat Serum. Toxicology, 47, 235-245. http://dx.doi.org/10.1016/0300-483X(87)90054-0

[26] Madhavan, N.D. and Naidu, K.A. (1995) Polycyclic Aromatic Hydrocarbons in Placenta, Maternal Blood, Umbilical Cord Blood and Milk of Indian Women. Human \& Experimental Toxicology, 14, 503-506. http://dx.doi.org/10.1177/096032719501400607

[27] Minh, T.B., Watanabe, M., Kajiwara, N., Iwata, H., Takahashi, S., Subramanian, A., et al. (2006) Human Blood Monitoring Program in Japan: Contamination and Bioaccumulation of Persistent Organochlorines in Japanese Residents. Archives of Environmental Contamination and Toxicology, 51, 296-313. http://dx.doi.org/10.1007/s00244-004-0251-5

[28] Anderson, L.M., Jones, A.B., Miller, M.S. and Chauhan, D.P. (1989) Metabolism of Transplacental Carcinogens. IARC Scientific Publications, 96, 155-188.

[29] Jedrychowski, W., Perera, F.P., Tang, D.L., Stigter, L., Mroz, E., Flak, E., et al. (2012) Impact of Barbecued Meat Consumed in Pregnancy on Birth Outcomes Accounting for Personal Prenatal Exposure to Airborne Polycyclic Aromatic Hydrocarbons: Birth Cohort Study in Poland. Nutrition, 28, 372-377. http://dx.doi.org/10.1016/j.nut.2011.07.020

[30] Choi, H., Wang, L., Lin, X.H., Spengler, J.D. and Perera, F.P. (2012) Fetal Window of Vulnerability to Airborne Polycyclic Aromatic Hydrocarbons on Proportional Intrauterine Growth Restriction. PLoS ONE, 7, e35464.

http://dx.doi.org/10.1371/journal.pone.0035464 
Scientific Research Publishing (SCIRP) is one of the largest Open Access journal publishers. It is currently publishing more than 200 open access, online, peer-reviewed journals covering a wide range of academic disciplines. SCIRP serves the worldwide academic communities and contributes to the progress and application of science with its publication.

Other selected journals from SCIRP are listed as below. Submit your manuscript to us via either submit@scirp.org or Online Submission Portal.
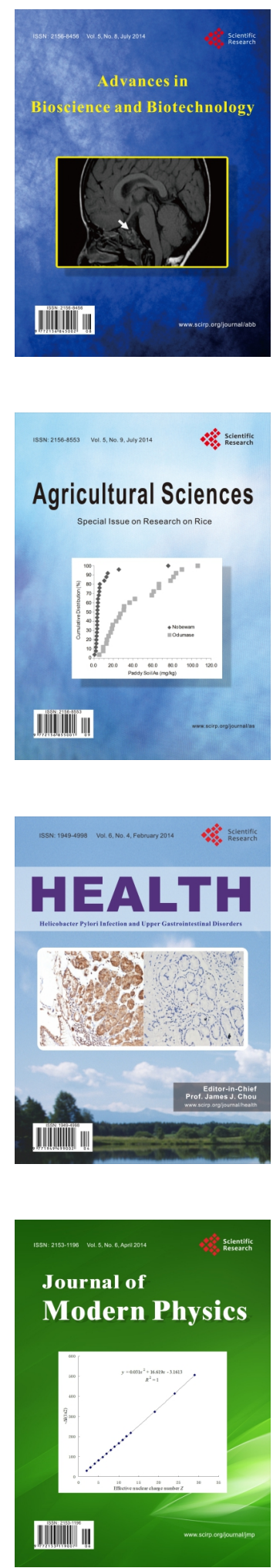
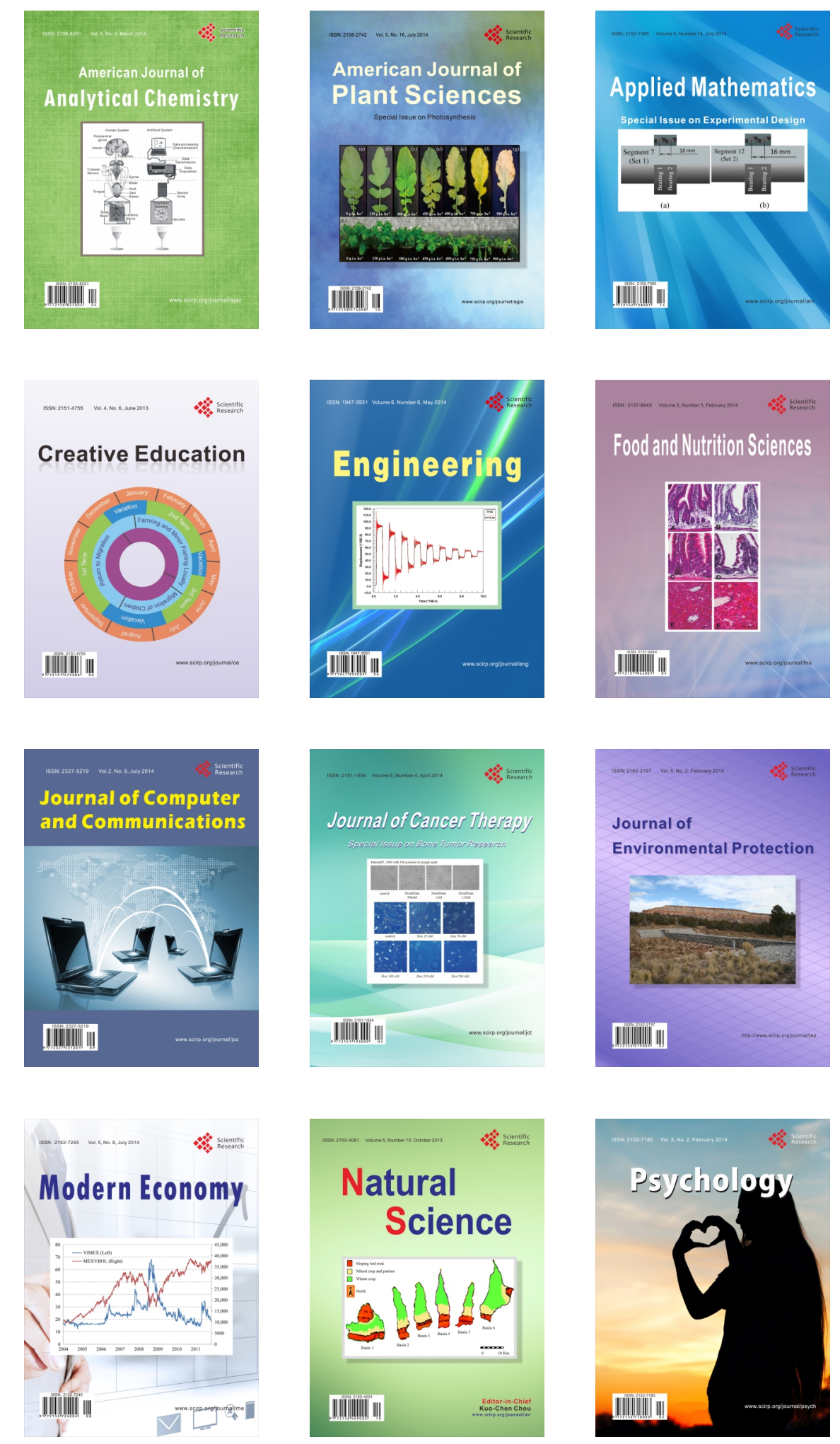